\title{
Single-Stage Complete Repair versus Multistage Repair of Tetralogy of Fallot with Borderline Pulmonary Arteries
}

\author{
Mohammed Dawoud, MS, MBBCh, ${ }^{1}$ Mohammed Abd Al Jawad, MD, ${ }^{2}$ Tamer Hikal, MD, ${ }^{2}$ \\ Khaled Samir, MD, PhD, FECTS ${ }^{2}$ \\ ${ }^{1}$ Department of Cardiothoracic Surgery, Al Ahrar Hospital, Zagazig; ${ }^{2}$ Department of Cardiothoracic Surgery, Ain Shams \\ University, Cairo, Egypt
}

\section{ABSTRACT}

Background: Tetralogy of Fallot is the most common cyanotic congenital heart defect. Borderline pulmonary anatomy has been associated with a higher risk of mortality and morbidity. Strategies to manage this condition-namely, singleor multistage repair-have long been debated.

Objective: The overall outcomes of patients with tetralogy of Fallot with borderline pulmonary arteries (McGoon ratio 1.3 to 1.7) with regard to the need for a single-stage or multistage repair and the outcome of each surgical management were evaluated.

Patients and methods: A retrospective, nonrandomized comparative study designed to evaluate patient outcomes comprised 60 patients with tetralogy of Fallot with borderline pulmonary arteries who underwent surgery at the Cardiothoracic Surgery Academy, Ain Shams University, Cairo, Egypt, between January 2016 and December 2017. After gaining approval from the affiliated ethical and research committee, and informed consent of the guardians, the patients were assigned into one of two groups. Shunt group included 30 patients managed surgically by a modified Blalock-Taussig (MBT) shunt as a part of a multistage repair, and repair group included 30 patients managed surgically by single-stage complete repair. The medical records of the patients were reviewed, and data relating to age, sex, weight, and preoperative oxygen saturation were collected. All patients underwent preoperative echocardiography and multislice computed tomography (CT) with angiography. The follow-up was performed by echocardiography at discharge and at one month and six months after surgery. Multislice CT with angiography was performed in patients who received a shunt once the echocardiography showed acceptable pulmonary arteries.

Results: The patients' age ranged from 5 to 50 months with a mean age of $18.63 \pm 9.15(19.84 \pm 12.34$ for the shunt group and 17.43 \pm 8.54 for the repair group). The weight ranged from $5 \mathrm{~kg}$ to $18 \mathrm{~kg}$ with a mean of $9.6 \pm 2.53(8.82 \pm 2.79$ for the shunt group and 10.41 \pm 2.63 for the repair group). The mean preoperative $\mathrm{O}_{2}$ saturation

Received June 25, 2018 ; received in revised form September 19, 2018; accepted September 28, 2018.

Correspondence: Dr. Mohammed Abd Al Jawad, MD, Department of Cardiothoracic Surgery, Ain Shams University, Abbaseya Square, 34 Abd Al Aziz Fahmy St., Heliopolis, Cairo, Egypt 11351; +201111219461 (e-mail: mohammed_abdaljawad@med.asu.edu.eg). was $68.95 \% \pm 7.8 \%$ for the shunt group and $87.93 \% \pm 6.18 \%$ for the repair group. The median McGoon ratio was 1.4 for the shunt group and 1.6 for the repair group, the difference of which was highly significant $(P<.0001)$. The mortality rate in our study was $10 \%(10 \%$ for the shunt group and $10 \%$ for the repair group). The morbidity incidence rate was $26.6 \%$ for the shunt and repair groups. The ICU stay ranged from 2 to 31 days, with a median of three days for the shunt group (mean $3.61 \pm 1.91$ ) and four days for the repair group (mean $6.07 \pm 6.63$ days). The calculated $P$ value showed a significant difference between the two groups concerning ICU stay. The postoperative $\mathrm{SO} 2$ significantly increased to a mean of $85.58 \pm 7.05$ in the shunt group and $98.14 \pm 3.36$ in the repair group $(P<.0001)$.

Conclusion: There was no statistically significant difference between multistage repair and single-stage complete repair regarding morbidity and mortality. Regarding ICU stay, patients in the single-stage had a better outcome. A McGoon ratio of 1.5 can be used as a guideline in the decision-making process.

\section{INTRODUCTION}

Tetralogy of Fallot is a congenital cardiac malformation consisting of a ventricular septal defect (VSD), aortic overriding, infundibular pulmonary obstruction, and right ventricular hypertrophy [Anderson 1981].

It is the most common cyanotic heart disease, with a prevalence from 0.21 to 0.36 per 1000 live births and comprising approximately 7 to 10 percent of all forms of congenital heart diseases [Ferencz 1985; Mitchell 1971].

Tetralogy of Fallot had been uniformly lethal, but this changed after the introduction of the systemic to pulmonary shunt by Alfred Blalock. On November 29, 1944, he performed the first operation on a cyanotic 1-year-old child with tetralogy of Fallot. The Blalock-Taussig shunt had a high rate of success, and, by 1950, 1000 operations involving this shunt had been performed by Blalock and his team [Taussig 1979].

The first intracardiac repair of tetralogy of Fallot was performed by C. Walton Lillehei and his team at the University of Minnesota using controlled cross circulation. In 1955, Kirklin and colleagues used the first pump oxygenator to perform a total repair [Neill 1994].

The mortality rate in cases managed by single-stage complete repair has decreased substantially. Among 10 surgeries performed by Dr. Lillehei, only 6 of the patients survived [Lillehei 1955]. However, mortality was $0.5 \%$ among 
Table 1. Comparison between Shunted and Repaired Patients with Regard to Preoperative Data

\begin{tabular}{lccc}
\hline & $\begin{array}{c}\text { Shunt Group } \\
(\mathrm{n}=30)\end{array}$ & $\begin{array}{c}\text { Repair Group } \\
(\mathrm{n}=30)\end{array}$ & $P$ \\
\hline \multicolumn{1}{c}{ Female, $\mathrm{n}(\%)$} & $13(43.3)$ & $9(30)$ & .4216 \\
$\quad$ Male, $\mathrm{n}(\%)$ & $17(56.7)$ & $21(70)$ & \\
Age, month & $19.8(12-24)$ & $14.5(12-21)$ & .338 \\
Weight, kg & $8.8(9-11)$ & $10(8-10)$ & .008 \\
Preoperative & & & \\
O, saturation, mmHg & $69(68-72)$ & $90(85-92)$ & $<.0001$ \\
MPA, mm & $6.4(6.2-7.1)$ & $7(5.7-8.5)$ & .183 \\
RPA, mm & $5.9(5.3-6.3)$ & $6.3(5.5-7.8)$ & .092 \\
LPA, mm & $6(5.7-7)$ & $6(5-7)$ & .994 \\
McGoon ratio & $1.4(1.4-1.5)$ & $1.6(1.6-1.7)$ & $<.0001$ \\
VSD, mm & $11.8(11.8-12.5)$ & $9.15(8-10)$ & $<.0001$ \\
RVOT gradient, mmHg & $79(79-84)$ & $80.5(75-94)$ & .164 \\
Aortic overriding degree & $50(50-50)$ & $50(40-50)$ & .513 \\
\hline
\end{tabular}

Values are shown as median (range) where indicated.

Bold indicates statistically significant $P$ value.

MPA indicates main pulmonary artery; RPA, right pulmonary artery; LPA,

left pulmonary artery; RVOT, right ventricular outflow tract.

366 patients between 1980 and 1991 as reported by Roger Mee and his colleagues [Karl 1992], and it decreased further to $0 \%$ in a series of 102 patients (average age 5.9 months) at Children's Memorial Hospital in Chicago between 1997 and 2004 [Stewart 2005].

Even so, some centers still perform systemic to pulmonary shunts, especially modified Blalock-Taussig (MBT) shunts, during the neonatal period followed by complete repair later on [Morales 2009].

Although recent studies have shown equivalent ICU stays and survival between the two strategies [Kanter 2010], surgical management of tetralogy of Fallot is still a hotly debated topic, notably whether to perform single-stage complete repair or systemic to pulmonary shunt surgery and delaying the complete repair. Determining when to implement each surgical strategy and which patients would most benefit from these strategies are highly complicated subjects [Stewart 2013].

Pulmonary artery size is an important prognostic factor in managing tetralogy of Fallot because there is a risk of right ventricular failure if the outflow resistance remains too high after separating the pulmonary and systemic circulations [Laas 1985].

\section{PATIENTS AND METHODS}

A retrospective, nonrandomized comparative study designed to evaluate patient outcomes comprised 60 patients with tetralogy of Fallot with borderline pulmonary arteries who underwent surgery at the Cardiothoracic Surgery Academy, Ain
Table 2. Intraoperative Data*

\begin{tabular}{lc}
$\begin{array}{l}\text { Variable, Shunt Group } \\
\text { Shunt size, mm } \\
4\end{array}$ & $\mathrm{n}(\%)$ \\
5 & $8(26.7)$ \\
Shunt site & $22(73.3)$ \\
Right & $\mathrm{n}(\%)$ \\
Left & $26(86.6)$ \\
Variable, Repair Group & $4(13.3)$ \\
Bypass time, min & \\
Cross-clamp time, min & $99.16 \pm 49.22(25-293)$ \\
\hline *Values are shown as median (range) where indicated
\end{tabular}

Shams University, Cairo, Egypt, between January 2016 and December 2017. After approval from the affiliated ethical and research committee and informed consent from the guardians were obtained, patients were classified into two groups. Shunt group: 30 patients managed surgically by an MBT shunt as a part of a multistage repair; repair group: 30 patients managed surgically by single-stage complete repair. The study included patients with a preoperative McGoon ratio (the ratio of the sum of both pulmonary artery diameters just before their bifurcations and the diameter of the descending aorta at the level of the diaphragm) between 1.3 and 1.7.

The medical records of the patients were reviewed, and age, sex, weight, and preoperative oxygen saturation data were collected. All patients underwent preoperative echocardiography and multislice computed tomography with angiography. Postoperative data, including oxygen saturation, ICU stay, hospital stay, morbidities, and mortality were collected.

All MBT shunts were performed via median sternotomy. The choice of shunt size was based on the patient's weight: a 4-mm shunt was used for individuals weighing $4-8 \mathrm{~kg}$, and a 5 -mm shunt was used for those $>8 \mathrm{~kg}$. Low-dose heparin (1 $\mathrm{mg} / \mathrm{kg})$ was given before opening the shunt. Air $\left(21 \% \mathrm{O}_{2}\right)$ was used for ventilation after declamping.

In single-stage complete repair, surgery was performed utilizing standard techniques of cardiopulmonary bypass, moderate hypothermia, and antegrade cold crystalloid cardioplegia. The transatrial transpulmonary approach was applied to all patients. First, the right atrium (RA) was opened, and the anatomy was examined. The VSD was closed, and infundibular resection was then performed via transatrial approach and, if required, was completed through a pulmonary arteriotomy. If the annulus was found to be inadequate, a transannular patch was utilized.

The follow-up was performed by echocardiography at discharge and at one month and six months after surgery. Multislice computed tomography with angiography was performed in patients who received a shunt once the echocardiography showed acceptable pulmonary arteries. The study was conducted between January 2016 and December 2017. 
Table 3. Comparison of Postoperative Data between Shunt and Repair Patients

\begin{tabular}{lccc}
\hline & $\begin{array}{c}\text { Shunt Group } \\
(\mathrm{n}=30)\end{array}$ & $\begin{array}{c}\text { Repair Group } \\
(\mathrm{n}=30)\end{array}$ & $\mathrm{P}$ \\
\hline $\mathrm{O}_{2}$ saturation, postop & $85(85-88)$ & $99(98-100)$ & $<.0001$ \\
$\mathrm{ICU}$ stay, d & $3(3-4)$ & $4(3.75-5.25)$ & .0058 \\
$\begin{array}{l}\text { Hospital stay, d } \\
\mathrm{O}_{2} \text { saturation, before } \\
\text { discharge }\end{array}$ & $86(7.5-9)$ & $9(7-10)$ & .254 \\
\end{tabular}

Values are shown as median (range) where indicated.

Bold indicates statistically significant $P$ value.

The primary ending point of the study was mortality. Postoperative oxygen saturation, ICU stay, hospital stay, postoperative complications, and NYHA class were considered secondary endpoints.

\section{Statistical Analysis}

Data entry, data processing, and statistical analysis were carried out using MedCalc version 15.8. Tests of significance (Pearson chi-square test, Student t test, ANOVA, repeated measures ANOVA, Pearson correlation coefficient) were used. Data are presented, and proper analysis was performed according to the type of data (parametric and nonparametric) obtained for each variable. A $P$ value of less than $.05(5 \%)$ was considered statistically significant. Descriptive statistics included: (1) mean, standard deviation $( \pm$ SD) and range for parametric numerical data; median and interquartile range (IQR) for nonparametric numerical data; and (2) frequency and percentage for nonnumerical data. Analytical statistics included: (1) Mann-Whitney $U$ test was used to assess the statistical significance of the difference of a nonparametric variable between two study groups; (2) Pearson chi-square test was used to examine the relationship between two qualitative variables; (3) ANOVA was used to assess the statistical significance of the difference of the means among more than two study groups; (4) repeated measures and factorial ANOVA tests were used to assess the statistical significance of the difference between more than two (paired) study group means, with the ability to insert grouping factors, which was used to generate clustered multiple variable graphs; (5) linear regression was used to test and estimate the dependence of a quantitative variable based on its relationship with a set of independent variables.

\section{RESULTS}

The patients' demographics and preoperative data are shown in Table 1 . The patient age ranges from 5 to 50 months with a mean age of $18.63 \pm 9.15(19.84 \pm 12.34$ for the shunt group and $17.43 \pm 8.54$ for the repair group). There were 21 infants $(35 \%)$ and 39 children (65\%). The weight ranged from $5 \mathrm{~kg}$ to $18 \mathrm{~kg}$, with a mean of $9.6 \pm 2.53(8.82 \pm 2.79$
Table 4. Postoperative Complications and Mortality

\begin{tabular}{lcc}
\hline Complication, $\mathrm{n}(\%)$ & Shunt Group $(\mathrm{n}=30)$ & Repair Group $(\mathrm{n}=30)$ \\
\hline Bleeding & $2(6.7)$ & $1(3.3)$ \\
Neurological & $0(0)$ & $2(6.7)$ \\
Renal impairment & $1(3.3)$ & $0(0)$ \\
Arrhythmias & $0(0)$ & $1(3.3)$ \\
Chest infection & $2(6.7)$ & $3(10)$ \\
Wound infection & $2(6.7)$ & $2(6.7)$ \\
Pericardial effusion & $0(0)$ & $1(3.3)$ \\
Shunt occlusion & $1(3.3)$ & - \\
Mortality & $3(10)$ & $3(10)$
\end{tabular}

for the shunt group and $10.41 \pm 2.63$ for the repair group), with a highly significant difference between the two groups $(P=.008)$. Additionally, the $\mathrm{O}_{2}$ saturation was $68.95 \pm 7.8 \%$ for the shunt group and $87.93 \pm 6.18 \%$ for the repair group; again, there was a highly significant difference between the two groups $(P<.0001)$. The median McGoon ratio was 1.4 for the shunt group and 1.6 for the repair group (Table 1).

Most shunt group patients received a $5-\mathrm{mm}$ shunt (73\%), and most patients $(86.6 \%)$ had the shunt placed on the right side (Table 2).

The mean bypass time in the repair patients was $99.16 \pm$ 49.22 minutes, and the cross-clamp time was $56.63 \pm 24.12$ minutes (Table 2).

The postoperative oxygen saturation improved significantly in both groups (median, $85 \%$ in the shunt group; $99 \%$ in the repair group). The ICU stay ranged from 2 to 31 days (median, 3 days for the shunt group (mean 3.61 \pm 1.91 ); and 4 days for the repair group (mean $6.07 \pm 6.63$ days). The overall hospital stay ranged from 5 to 50 days (median, 8 days for the shunt group (mean $8.47 \pm 3.54$ ); and 9 days for the repair group (mean $11.37 \pm 9.62$ ). The comparative study between the two groups revealed a highly significant increase in the ICU stay in the repair group compared to the shunt group $(P$ $=.0058)$ but revealed a nonsignificant difference with regard to overall hospital stay $(P>.05)$ (Table 3$)$.

There was no significant difference in postoperative morbidity between the shunt and repair groups (Table 4).

In the shunt group, 8 patients $(26.6 \%)$ suffered from postoperative complications. Shunt obstruction occurred in 1 patient after discharge, who needed another operation. Renal impairment requiring peritoneal dialysis occurred in 1 patient and eventually resolved; this resulted in a more extended ICU stay (9 days) for this patient. Chest infection occurred in 2 patients, wound infection occurred in 2 patients, and bleeding occurred in 2 patients (Table 4).

In the repair group, 8 patients $(26.6 \%)$ suffered from postoperative complications. Two of these patients suffered from brain insult and chest infection, both of whom required more extended ICU stays (31 days and 27 days). Another patient suffered from chest infection. Localized pericardial effusion occurred in 1 patient, but reintervention was not needed. Two 

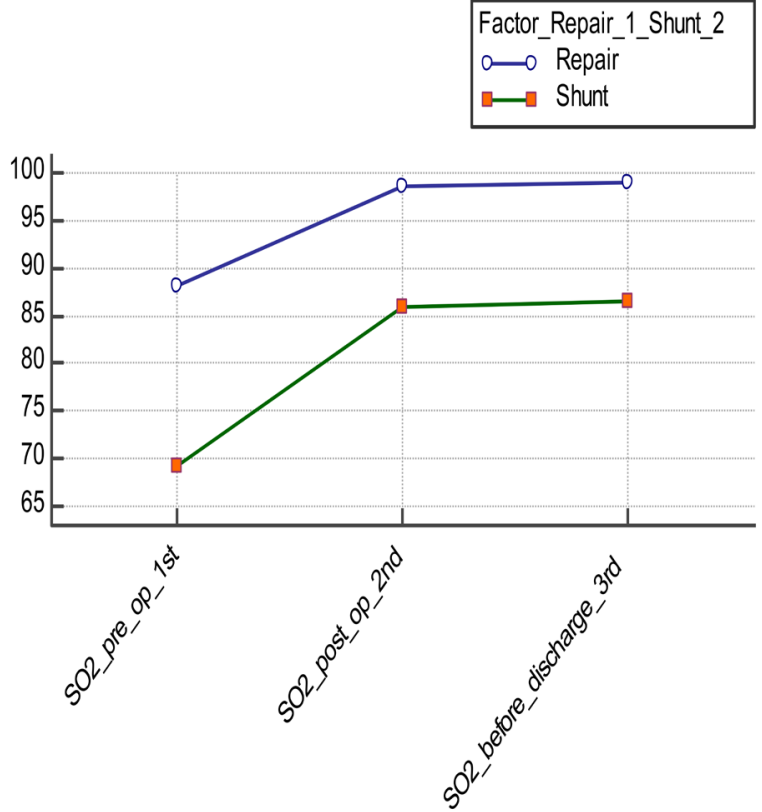

Comparison between repair group $(n=30)$ and shunt group $(n=30)$ with regard to serial $\mathrm{O}_{2}$ saturation.

patients had a wound infection, one patient suffered from postoperative bleeding and required intervention, and one patient suffered from supraventricular tachycardia (Table 4).

The incidence of mortality in our study was $10 \%(10 \%$ for the shunt group and 10\% for the repair group) (Table 4).

We used oxygen saturation and the NYHA score to assess patients after surgery. A comparative study between pre- and postoperative measurements for the shunt and repair groups revealed that the average $\mathrm{SO} 2$ significantly increased during serial $\mathrm{O}_{2}$ saturation measurements, with a highly significant difference $(P<.0001)$ (Figure).

Approximately $73.3 \%$ of the shunt group and $83.3 \%$ of the repair group had an NYHA score of Grade 1 (Table 5).

\section{DISCUSSION}

Even with the recent significant advances in congenital heart surgery, the management of tetralogy of Fallot remains challenging, especially regarding the choice between performing single-stage complete repair or performing systemic to pulmonary shunt surgery and delaying complete repair. Identifying when each surgical strategy should be applied and which patients would benefit most from both strategies are still not fully elucidated. The choice of repair or shunt will affect the practical decision, notably whether to perform a transannular patch, and will also be affected by resources, equipment, and experience of the surgeons at the institution. Our study showed that the morbidities, whether for the shunt group or the repair group, was comparable to those from developing countries but higher than those from developed countries. Additionally, according to mortality rates, our results are higher than those reported worldwide, especially
Table 5. Comparison between Shunt and Repair Groups According to Postoperative NYHA Score

\begin{tabular}{lccc}
\hline NYHA score, $\mathrm{n}(\%)$ & $\begin{array}{c}\text { Shunt Group } \\
(\mathrm{n}=30)\end{array}$ & $\begin{array}{c}\text { Repair Group } \\
(\mathrm{n}=30)\end{array}$ & $P$ \\
\hline Grade 1 & $22(73.3)$ & $25(83.3)$ & .6024 \\
Grade 2 & $4(13.3)$ & $2(6.7)$ & \\
Grade 3 & $1(3.3)$ & $0(0)^{*}$ \\
Grade 4 & $0(0)^{*}$ & $0(0)^{*}$ \\
\hline
\end{tabular}

*Patients with this score died during the study.

those from developed countries [Gladman 1997; Jahangiri 1999; Maghur 2002; Singh 2014; Hirsch 2000; Dyamenahalli 2000; Anagnostopoulos 2007; Allam 2014; Sasikumar 2014; Saygi 2015].

Although we found no difference between the shunt and repair groups regarding morbidity and mortality, there was still a significantly shorter ICU stay for the shunt group. It should be noted when analyzing these results that the repair group in this study had a higher weight, higher preoperative SO2, and higher McGoon ratio. Additionally, there was a significant improvement in morbidity and mortality after shunt operation, which was comparable to that of single-stage repair.

We were limited to tetralogy of Fallot patients with borderline pulmonary arteries and those who had a McGoon ratio between 1.3 and 1.7. Even with the development of other methods to estimate pulmonary arterial size, the McGoon ratio is still used in Egypt, as it is available and practical and can be calculated by the surgeon. Additionally, it is still used in many reports, especially those from developing countries [Chen 2007].

We found that the median McGoon ratio was 1.4 for the shunt group and 1.6 for the repair group, which was significantly different $(P<.0001)$. This suggests a ratio of 1.5 as a differentiating point for determining the optimal surgical strategy.

Recent studies revealed that single-stage complete repair could be performed with a low risk of mortality and with survival rates equal to those of two-stage repair, even in younger patients [Stewart 2005; Kanter 2010; Karl 1992].

One of the critical challenges is the size of the pulmonary arteries. The application of MBT shunts has been found to promote the growth of pulmonary arteries, decrease the use of transannular patches, and facilitate subsequent repair [Kanter 2010; Jahangiri 1999; Ishikawa 2001; Sabri 1999; Ross 2015]. Complications of the MBT shunt still exist, thus adding another prognostic factor that should be kept in mind, especially as it relates to pulmonary artery distortion and stenosis [Gladman 1997].

Even with the growing interest in primary repair, the data regarding aggressive patch augmentation of the hypoplastic pulmonary arteries found that this strategy may lead to late-onset stenosis and higher rates of reintervention [Wilder 2016]. Additionally, the occurrence of pulmonary incompetence with the use of transannular patches has an unfavorable 
effect on the long-term recovery after repair [Singh 2014; Horneffer 1990; Frigiola 2004].

Shunted patients required fewer transannular patch repairs despite undergoing more new initial operations [Laas 1985].

If the two-stage strategy is to be used, patients should be thoroughly followed up after shunt operation to avoid and detect any complications until complete repair can be implemented.

\section{Study Limitations}

The study still requires further development in determining whether adding the postoperative repair results of a two-stage strategy will make a difference, if there is an actual decrease in the use of transannular and pulmonary patches with this strategy, and if these benefits outweigh the risk of undergoing two operations. Additional limitations of the study are as follows: the limited number of patients, the limited follow-up time, and the intraoperative decision-making at the discretion of the operating surgeon rather than strict adherence to the protocol.

\section{Conclusion}

There was a significant improvement after the MBT shunt with no significant difference between the shunt and single-stage complete repair regarding morbidity and mortality. However, regarding the ICU stay, the multistage repair was better with fewer postoperative severe complications. There is no significant difference between multistage repair (after the first stage) and single-stage complete repair. Proper decision-making can be performed using the McGoon ratio; however, intraoperative evaluation of the pulmonary arteries should still be performed. A McGoon ratio of 1.5 could be used as a cutoff in management decision-making.

The MBT shunt is a palliative first-stage surgery and is still a good option in managing tetralogy of Fallot (even with the increased interest of single-stage complete repair), especially in complex cases and in poorly equipped institutions, with good postoperative results. Patient follow-up after MBT shunt is significant.

Every effort should be made to improve the environment of heart surgery in Egypt, and more studies are needed to identify specific guidelines about tetralogy of Fallot management, primarily in developing countries.

\section{REFERENCES}

Allam A, Hashem A. 2014. Fate of right ventricle outflow gradient after fallot repair. J Egyptian Soc Cardiorthorac Surg 22:53-8.

Anagnostopoulos P, Azakie A, Natarajan S, Alphonso N, Brook MM, Karl TR. 2007. Pulmonary valve cusp augmentation with autologous pericardium may improve early outcome for tetralogy of Fallot. J Thorac Cardiovasc Surg 133:640-7.

Anderson RH, Path MRC, Allwork SP, Ho SY, Lenox CC, Zuberbuhler JR. 1981. Surgical anatomy of tetralogy of fallot. J Thorac Cardiovasc Surg 81:887-96.

Chen B-B, Chen S-J, Wu M-H, Li YW, Lue HC. 2007. EBCT - McGoon ratio. A reliable and useful method to predict pulmonary blood flow noninvasively. 32:1-8.
Dyamenahalli U, McCrindle BW, Barker GA, Williams WG, Freedom RM, Bohn DJ. 2000. Influence of perioperative factors on outcomes in children younger than 18 months after repair of tetralogy of Fallot. Ann Thorac Surg 69:1236-42.

Ferencz C, Rubin JD, McCarter RJ, et al. 1985. Congenital heart-disease: prevalence at livebirth. The Baltimore Washington Infant Study. Am J Epidemiol 121:31-6.

Frigiola A, Redington AN, Cullen S, Vogel M. 2004. Pulmonary regurgitation is an important determinant of right ventricular contractile dysfunction in patients with surgically repaired tetralogy of Fallot. Circulation 110: II153-7.

Gladman G, McCrindle BW, Williams WG, Freedom RM, Benson LN. 1997. The modified Blalock-Taussig shunt: Clinical impact and morbidity in Fallot's tetralogy in the current era. J Thorac Cardiovasc Surg 114:25-30.

Hirsch JC, Mosca RS, Bove EL. 2000. Complete repair of tetralogy of Fallot in the neonate. Results in the modern era. Ann Surg 232:508-14.

Horneffer PJ, Zahka KG, Rowe SA, et al. 1990. Long-term results of total repair of tetralogy of fallot in childhood. Ann Thorac Surg 50:179-85.

Ishikawa S, Takahashi T, Sato Y, et al. 2001. Growth of the pulmonary arteries after systemic-pulmonary shunt. Ann Thorac Cardiovasc Surg 7:337-40.

Jahangiri M, Lincoln C, Shinebourne EA. 1999. Does the modified Blalock-Taussig shunt cause growth of the contralateral pulmonary artery? Ann Thorac Surg 67:1397-9.

Kanter KR, Kogon BE, Kirshbom PM, Carlock PR. 2010. Symptomatic neonatal tetralogy of Fallot: repair or shunt? Ann Thorac Surg 89:858-63.

Karl TR, Sano S, Pornviliwan S, Mee RBB. 1992. Tetralogy of fallot: favorable outcome of nonneonatal transatrial, transpulmonary repair. Ann Thorac Surg 54:903-7.

Laas J, Engeser U, Meisner H, et al. 1984. Tetralogy of fallot: development of hypoplastic pulmonary-arteries after palliation. Thorac Cardiovasc Surg 32:133-8.

Lillehei CW, Cohen M, Warden HE, et al. 1955. Direct vision intracardiac surgical correction of the tetralogy of fallot, pentalogy of fallot, and pulmonary atresia defects: report of 1 st 10 cases. Ann Surg 142:418-45.

Maghur HA, Ben-Musa AA, Salim ME, Abuzakhar SS. 2002.The modified Blalock-Taussig shunt: A 6-year experience from a developing country. Pediatr Cardiol 23:49-52.

Mitchell SC, Korones SB, Berendes HW. 1971. Congenital heart disease in 56,109 births: incidence and natural history. Circulation 43:323-32.

Morales DL, Zafar F, Fraser Jr CD. 2009. Tetralogy of Fallot repair: the right ventricle infundibulum sparing (RVIS) strategy. Semin Thorac Cardiovasc Surg Pediatr Card Surg Annu 54-8.

Neill CA, Clark EB. 1994. Tetralogy of fallot: the 1 st 300 years. Texas Hear Inst J 21:272-9.

Stewart RD, Mavroudis C, Backer CL. 2013. Pediatric Cardiac Surgery, Fourth Edition. Eds: Mavroudis C and Backer CL. Blackwell Publishing Ltd. p. 415.

Ross ET, Costello JM, Backer CL, Brown LM, Robinson JD. 2015. Right ventricular outflow tract growth in infants with palliated tetralogy of fallot. Ann Thorac Surg 99:1367-72.

Sabri MR, Sholler G, Hawker R, Nunn G. 1999. Branch pulmonary artery growth after Blalock-Taussig shunts in tetralogy of Fallot and pulmonary atresia with ventricular septal defect: A retrospective, echocardiographic 
study. Pediatr Cardiol 20:358-63.

Sasikumar D, Sasidharan B, Tharakan JA, Dharan BS, Mathew T, Karunakaran J. 2014. Early and 1-year outcome and predictors of adverse outcome following monocusp pulmonary valve reconstruction for patients with tetralogy of Fallot: A prospective observational study. Ann Pediatr Cardiol 7:5-12.

Saygi M, Ergul Y, Tola HT, et al. 2015. Factors affecting perioperative mortality in tetralogy of Fallot. Pediatr Int 57:832-9.

Singh SP, Chauhan S, Choudhury M, et al. 2014. Modified Blalock Taussig shunt: Comparison between neonates, infants, and older children.
Ann Card Anaesth 17:191-7.

Stewart RD, Backer CL, Young L, Mavroudis C. 2005. Tetralogy of Fallot: Results of a pulmonary valve-sparing strategy. Ann Thorac Surg 80:1431-9

Taussig HB. 1979. Tetralogy of fallot: early history and late results. Am J Roentgenol 133:423-31.

Wilder TJ, Van Arsdell GS, Pham-Hung E, et al. 2016. Aggressive patch augmentation may reduce growth potential of hypoplastic branch pulmonary arteries after tetralogy of Fallot repair. Ann Thorac Surg 101:996-1004. 